\title{
Investigación \\ La ciudad de la memoria. Devenir de los discursos de representación
}

Fernando R. de la Flor

Catedrático del Dpto. de Literatura Española. Universidad de Salamanca

\section{Resumen}

Los discursos de la representación y de la implementación de lo simbólico apenas tienen un punto común con el proceso material que en la segunda mitad del siglo XX siguieron las ciudades españolas a las que podemos denominar como "capitales de la memoria", y entre las cuales resulta sumamente emblemática Salamanca. El texto que sigue trata de deconstruir y reducir al plano de la evidencia toda la arquitectura metafórica y la identidad retórica y publicitaria que se ha elevado sobre el antiguo locus patriae, en realidad devastado por operaciones corsarias, y en cuya realidad actual el autor gusta más de señalar el peso de las sombras y de las ausencias, que la entidad misma, fragmentada y silenciada, de lo que ha podido sobrevivir a tiempos singularmente confusos.

\section{Palabras clave}

\section{Capital cultural}

Discurso de representación

Historia

Memoria

Patrimonio cultural

Salamanca
Cuanto abarca de bienes culturales el materialista histórico con la mirada, tiene, sin excepción, una procedencia que no puede contemplar sin prevención (W. Benjamin)

Años dos mil, siglo veintiuno. Momentos, sin duda, de cambio epocal, en los cuales las condiciones en que han existido hasta hoy y han sido pensadas las ciudades patrimoniales españolas entran en una nueva fase histórica, decisiva para su destino y modo de supervivencia.

Nueva "era", entonces, de la que, con seguridad, se puede ya afirmar que cambiará para siempre la significación de un conjunto de ciudades emblemáticas, de un ser y de una especificidad de la península y de "lo español", transformando hondamente el sentido que hasta hoy han adquirido en su pasaje por una historia compleja. Pues, en efecto, podemos decir de la memoria urbana, memoria de la ciudad o imago urbis que, en realidad, se diseña y rediseña culturalmente con el paso del tiempo.

La ciudad, su imaginario, cambia ciertamente, como quería el poeta Baudelaire, con más rapidez que lo hacen las generaciones que la habitan, dejando enseguida obsoletas las descripciones que se almacenan en su archivo.

El ser distintivo, lo que podríamos llamar el carácter, de estos primitivos núcleos urbanos y emplazamientos patrimoniales significativos, diseminados como reductos por la geografía peninsular, ha pasado a ocupar ahora, en los últimos años, una posición vital en el dispositivo imaginario de una industria de la cultura que necesita el pasado para ensayar cualquier porvenir. En términos del historiador italiano Assunto, es ahora, precisamente, cuando "la antigüedad se propone como futuro"1.

La fabricación para las masas del concepto enteramente novedoso de un ocio viajero y de un turismo cultural determina la creación en los territorios nacionales de una red de puntos nodales donde el pasado se sustantive, cobre una forma reconocible y se pueda, al fin, constituir como destino de desplazamientos y horizonte escénico de trayectos cualificados.

Se trata, en realidad, bajo diversas estrategias y matices, de la creación de grandes parques temáticos de la historia, donde ésta, al fin, estabilizada y domesticada, se mostrará entre nosotros al modo de un perfecto "museo" o inventario de lo que aún queda del ayer.

En estos "lugares de la memoria" se condensaría el depósito último de unos valores, de una idiosincrasia nacional, que acompañada de sus correspondientes morfologías, se encuentra en franco retroceso en todo otro lugar, debido a los efectos de unos modelos urbanos globalizados, que forman parte de un conurbación ya sin límites (y podríamos decir que sin marca precisa, más allá de venir a representar éstos el puro presente, sin profundidad ni densidad especifica alguna)

En el espiritu de esta determinación incrementada de lograr la identificación, el establecimiento y fijación de unos sacras o emblemas 
urbanísticos sobrevivientes del pasado, contrapuestos al presente que todo lo ocupa, y, por tanto, absolutamente necesarios para la economía simbólica de un país, la política misma y la planificación económica penetran hoy (lo hace en realidad desde hace ya decenios) la estructura hasta hace poco opaca y desplazada de la antes olvidada ciudad patrimonial o histórica española para extraer de ella una última rentabilidad y servicio. Esta intervención ideológico-urbanística convierte activamente las viejas urbes históricas en una suerte de nuevo fetiche cultural, sujeto a todas las estrategias transformativas posibles (la primera de ellas la implantación en la conciencia de masas de la accesibilidad a su encanto, la total entrega que se hace de su "misterio" histórico constitutivo).

Las estrategias que convierten de sujeto y protagonista, antes, en objeto paciente, ahora, el hecho de la ciudad histórica española, se mueven, tanto en el plano de las intervenciones "reales" o materiales, como en otra dimensión (no menos transformativa y eficaz) de los discursos que sobre la misma se tienden, en la esperanza (fracasada) de apresar su ser intangible, el "espíritu", siempre ambiguo y elusivo, en el que ha cuajado su historia tormentosa.

\section{Sin arquitectura no podemos recordar}

Pero la vieja, la altiva renuencia de ciudades emblemáticas, como esta de Salamanca de la que venimos finalmente a hablar; ciudad esencialmente pasadista desde antiguo poseída por una suerte de aversión a remodelarse, a modernizarse, a cambiar de estilo (o de spirit), que era cosa que tanto habian apreciado los viajeros conservadores y los filósofos de la tradición, es también ello mismo, y ahora, cosa ya del pasado. Más cuando, precisamente, la propia ciudad ha decidido abiertamente apoyarse en lo ya para ella ha sido, en lo histórico irremediablemente transcurrido y acaecido, para poder contar en algún futuro previsible, integrándose entonces, de una manera que no podemos tomar como "natural", en tanto que el espacio donde al fin también se realiza una suerte de coiné europea, y olvidando con ello toda una tradición severa de alejamiento de la modernidad y de la racionalidad occidental, cuyos destellos -digámoslo: cuya original extrañeza y otredad orgullosa- supo captar, con pulso maestro, en un momento que ya nos debe parecer fabulosamente lejano, la intuición unamuniana.

La vieja advertencia de Marinetti a los españoles, poseedores de un inigualable paisaje histórico y de una profundidad temporal cuajada en piedras y ciudades enteras, ha sido, al fin, inevitablemente desatendida. De nada parece haber servido aquella llamada que desde el fondo del Manifiesto futurista clamaba por que se impidiera "a los turistas millonarios venir a visitar vuestra España, como un ideal cementerio". Al fin se ha hecho manifiestamente cierta también aquella otra amenaza lejana para 1909: "Sé muy bien -continuaba el Manifiesto- que hay quien se esfuerza por alucinaros con las enormes ganancias que podría reportaros el comercio inteligente de vuestro glorioso pasado..."2.
Las élites políticas, financieras y culturales que han tomado las riendas de estos nuevos destinos ahora improvisados, no poseen en realidad respecto a estas ciudades-emblema (uno de cuyos modelos acrisolados bien podría ser Salamanca) otro valor de cambio que el del propio capital patrimonial, el cual, como en el cuento de la lechera, crece y crece en su imaginario (mientras, en la realidad, se erosiona y fragmenta, pues el espacio, especialmente el espacio construido, como nos han enseñado los filósofos de la estirpe heraclitea, "se deshace como la arena que se desliza entre los dedos". Finalmente, en efecto: "el tiempo se lo lleva todo, y sólo nos deja unos cuantos pedazos informes" -Paul Virilio-) $)^{3}$.

La remodelación y cambio de signo de la ciudad patrimonial está, pues, en marcha (en la dimensión cuasi militar del término). Puede decirse de tal proceso que, en general, busca transferir la carga trágica, la pesada herencia histórica de carácter absolutista y confesional que le cabe en tanto antigua ciudad hispana de naturaleza clericalizada, levítica e inquisitorial, ahora conducida hacia un review o disposición renovada de apertura lúdica, ilustrativa, pedagógica de bajo perfil, que pueda captar en la red de una real mercantilización de una activa macburguerización de los centros históricos- los primitivos lugares de significación dramática y espectacular Ancien Regime, ofrecidos ahora con free access al mayor número de miradas no especializadas.

La ciudad, pues, se abre. Salamanca, cittá apperta, podría ser el nuevo slogan, sin que en él desapareciera del todo la connotación estratégica que el término recibe en italiano y en otras lenguas: ciudad (al fin) "abierta", rendida, ciudad franca, ante la pujanza de lo extraño a ella, de lo no propio y extranjero. Con ello se consigue poner de rodillas al pasado, rebelde siempre, intratable y dogmático, y ello frente a los ídolos nuevos del presente, que hoy más que nunca muestran su decisivo poder de transformación en lo material, al tiempo que exhibe una capacidad inagotable de operar cualquier resemantización en el régimen de lo imaginario.

Este tránsito desde la vieja ciudad ocluida y oscura, levítica y penitencial del pasado a la ciudad expositiva (más bien, en términos de acuñación turística: "ciudad de exposiciones"), patrimonio cultural de una Humanidad que de ella poco sabe, ciudad ya sin clausura (ni misterio alguno), no se ha realizado sin grandes costes $y$, en todo caso, sin que ello afecte sobre todo al propio orden central de lo simbólico y de lo imaginario. Pero el mismo proceso ha supuesto también cambios y remodelaciones integrales en el ámbito más común y perceptible de lo visible, originando entonces las morfologías 0 , más propiamente, dejándolas habitar por el nuevo espiritu de una modernidad todopoderosa que en realidad desprecia y minusvalora la ejemplaridad suntuosa y dramática de lo pasado. La animadversión a tal pasado (tal y como fue; es decir siempre -e inevitablemente- tiránico, absolutista, confesional...) es parte de las pulsiones que organizan los mecanismos centrales que conducen el desarrollo y el progreso. 


\section{Investigación}

La ciudad de la memoria.

Devenir de los discursos

de representación

\section{Fernando R. de la Flor}

Puede decirse de Salamanca, en general, sin por ahora remontarse mucho más lejos, que su misma consagración como capital cultural, política y casi también "sentimental" del primer y más intempestivo franquismo, marcó decisivamente el proceso según el cual su pasado estaba obligado a hacerse cada día más opaco, hasta venir a caer en la total incomprensión y, en realidad, en el olvido despectivo mismo de todos los fantasmas regresivos que habían sido los verdaderos inventores, en la lejana temporalidad "fuerte", siglodorista, de esta singular ciudad, donde cuajó como en parte alguna la metafísica hispana.

Para esta "operación saldo", y hasta, cuando menos, operación olvido de la Salamanca producida por una España verdaderamente "negra" ha sido con todo necesario la combinación de dos fuerzas de signo contrario -arcaicas y conservadoras las unas; progresistas y modernizadoras, las otras-, las cuales han actuado, con rara unanimidad en este caso, al unisono, con el objetivo manifiesto de desvirtuar el significado real de esta auténtica Christianópolis (desactivando la carga potencial de una historia). Se trataba de maquillar al espectro de la temporalidad histórica, con el objeto de hacerlo revertir y confluir dulcemente en lo que hoy es un proceso general consensuado para la interpretación del pasado nacional, prontamente ya lavado de todas sus culpas, exonerado de su alto potencial desestructurador, nihilista, dramático.

De aquel primer y genuino fascismo, que tomó la ciudad como suya (como sucedió con tantas otras especialmente del interior de la Península), convirtiéndola en el Cuartel General de la España liberada, cabe decir que, al menos en su primer momento, no fue agresivo con la vieja ciudad del Tormes, y que, incluso, permitió por muchos años después de su elección como capital militar y moral del Régimen el que esa misma ciudad vegetara, somnolienta y abstraída en su pasado. Cosa que, en efecto, sucedió, por lo menos hasta el primer aldabonazo transformativo con que se dejó sentir la gran máquina de remodelación territorial (y espiritual) de España que fue el Primer Plan de Desarrollo, que empezó a engrasar el motor transformativo español por los años 50 .

Pero la agresividad constitutiva del nacional-catolicismo español no dejó por ello de mostrar cierta inquina y profundo malcontento, en definitiva, con una ciudad que, no habiendo sabido mantener en lo ideológico la tensión imperial a que como fábrica intelectual estaba destinada, se había dejado arrastrar a las profundidades de una gran decadencia, perdiendo la alta resonancia europea -vaciando de contenido el antiguo "renombre"- que algún día, ya por siempre muy lejano, había tenido.

Así, los proyectos urbanísticos de Victor D ' ors en los primeros cuarenta, con su retórica ampulosa y de signo neoclásico, trataron de cortar en seco hasta hacer olvidar esa decadencia pueblerina y curil en que estaba envuelta Salamanca, para recuperar in loco una perdida proyección cesárea, dominadora. Las perspectivas abiertas (pero sólo en el proyecto de papel) por aquel urbanista mediocre y soñador de una Roma imperial que realizar en la estepa castellana evidencian su estrategia de creación de espacios para el encuadramiento militarista de multitudes y la construcción de hitos conmemorativo-emblemáticos que destruyen por completo el deshilvanado casulario salmantino.

Las fantasías grandilocuentes (casi "speerianas", diriamos, atendiendo al fautor coetáneo de un Berlín capital de un reich milenario) de este modesto arquitecto del régimen en su primera hora convocaban, con fuerza imaginaria, el hecho de una capital transformada y rediseñada como potente núcleo de semanticidad dictatorial, casi gestionada "a la romana". Se pretendía con ello el incubar en ella misma la pretensión de configurar un día una gran urbs nova que, en el programa de sus ideólogos, se pudiera incluso proyectar como nueva metrópoli del concepto superior y global de Hispanidad, aprovechando con ello, más el anecdotario derivado de la fugaz estancia de Colón en la ciudad, que las evidencias ideológicas que podrian extraerse de los periodos de formación en el alma mater salmantina de Francisco Vitoria o, mucho menos, el padre Las Casas.

Estas trazas y diseños y, en realidad, esta primera utopía urbanística del falangismo cultural para ésta que fue su muy querida "capital moral" pronto se disolvió en el aire, y la ciudad pudo prolongar sus sueño, su "siesta" (en términos de Leopoldo Alas Clarín, el gran observador de la provincia hispana), más allá de lo que la propia lógica de los tiempos demandaba en punto a gestión del patrimonio y utilización estratégica de un pasado que, en lo que a la ciudad se refiere, permanecia todavía más bien virgen.

La no realización de obras de importancia en la ciudad salida de la guerra no quiere decir que este primer momento de epifanía y manifestación de una cultura primitiva de signo totalitario -el urfascismo español- fuera con la ciudad enteramente inofensivo. Los servicios de propaganda del Régimen continuaron una larga tradición salmantina que había hecho ya de la Ciudad de los Estudios un espacio muy preparado (por su escenografía y por sus figurantes, siempre entregados) para las manifestaciones representativas y espectaculares de un Antiguo Régimen que concebía en realidad espacio público y ciudad como un dominio publicitario de los valores que le daban soporte, y, además, que soñaban con ver convertidas sus calles en la escenografía ideal para su marcial determinación.

En esos primeros años de la lucha, la ciudad prestó el teatro de sus seculares espacios significativos para los grandes carnavales diplomáticos y fiestas significativas del Régimen, alcanzando un gran nivel sobre todo en las recepciones de los embajadores de las potencias del Eje (no en vano se evocaba aquí la fidelidad habsbúrgica, saltando por encima siglos de afrancesamiento borbónico, que en lo que a la ciudad respecta nada parecía por entonces contar).

No vale la pena recordarlo ahora, en el momento en que en este monográfico nos determinamos a revisar conceptos amplios relativos al proceso patrimonial, pero alguien tendrá algún día que historiar el modo en que las catedrales contrarreformistas y, sobre todo, la gran plaza ilustrada, construida por el "caballero" Llanes en la 


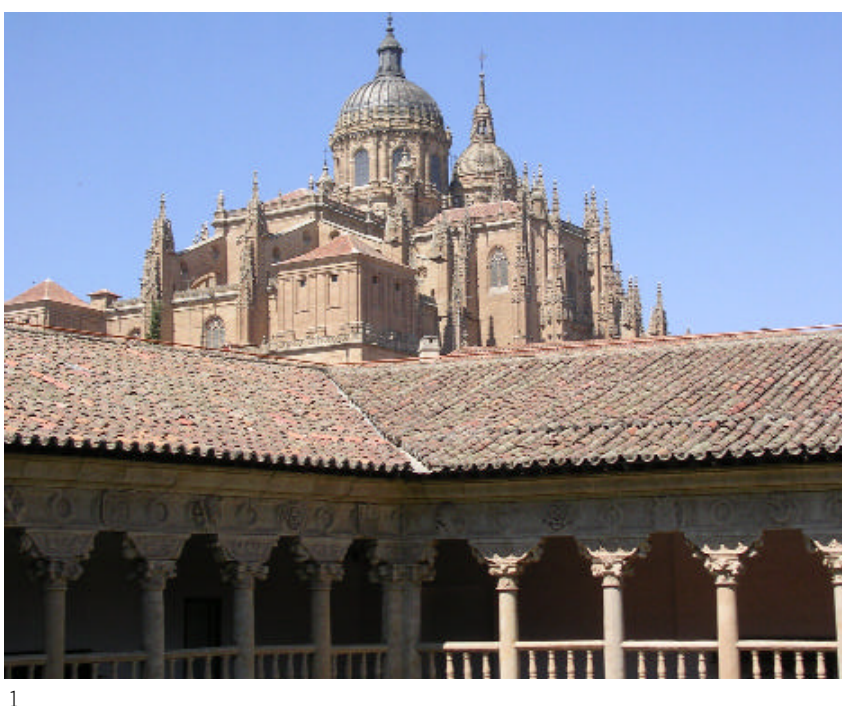

Salamanca más clásica, sirvieron como ideal telón de fondo a las primeras y potentes mascaradas político-religiosas de carácter nacional. Lo cual por algunos años fue de mucha admiración por las multitudes que en las ciudades menos espectaculares y dispuestas de la España plural veían estos festivales representativos bajo el prisma documentador del NO-DO.

El tiempo a veces parece invertirse y la llustración y el Neoclasicismo pueden no ser más que un momento pasajero en la historia de un sempiterno barroco hispano. Salamanca realizaba a la perfección ese ejercicio de memoria "barroca", como custodia de "sacras tradiciones", como osario, en realidad, donde quedaba definitivamente depositado el cuerpo incorrupto de la Santa España.

Esta capacidad de Salamanca para convertirse en "fachada" o telón de fondo del aparato celebrativo del Estado dañó profundamente su imagen en el exterior, convirtiéndola en una suerte de "ciudad nongrata" a los temperamentos demócrataliberales, que, en efecto, dejaron enseguida de habitarla y de visitarla.

No será, con todo, esa la única herida inferida a la ciudad patrimonial, pues si bien en el objetivo general de aquella política de utilización de la imagen consolidada de una Salamanca conservadora y tradicionalista figuraba, como dice hoy un poeta actual, el que gentes como Antonio Tovar -el consejero cultural de Franco más dotadotuvieran la intención de que "Roma fuera Salamanca", y como en aquella otra, asentar al fin en ésta la "basa, el fuste, el plinto y la planta" de una soñada España renacida, es también verdad que cuando esa intención acabó por mostrar su filo retórico, haciéndose realidad tan sólo en la elocuencia vacía del púlpito, de la cátedra o de la tribuna, el propio consejero Tovar montó en camiones las joyas bibliográficas de la depredada y triste Biblioteca de Estudios, y se fue con ese tesoro salmantino a Madrid, en busca de otros aires y, como se decía
1. En estos "lugares de la memoria" se condensaría el depósito último de unos valores, de una idiosincrasia nacional, que acompañada de sus correspondientes morfologías, se encuentra en franco retroceso en todo otro lugar, debido a los efectos de unos modelos urbanos globalizados, que forman parte de un conurbación ya sin límites

entonces, de otros "destinos" y servicios a la vieja patria, que en Salamanca, entretanto, quedaba en estado de perfecta automoribundia, degradada en lo urbanístico y sin pulso en lo social y cultural.

Entonces, por largos años, Salamanca se disolvió en su ruina y en su estancado mundo cultural sin pretensiones, un poco cociéndose en su propia salsa de ciudad de ínfima categoría en lo económico, en lo cultural, en lo turístico, incluso. De esos que fueron ominosos años, y aún décadas enteras -de los cincuenta, de los sesenta-, sólo quedan relatos parciales, esquirlas críticas que reconstruyen la imagen de un espacio profundamente depredado y a los que ahora no podemos volver para realizar la arqueología documentada de las pérdidas entonces producidas.

El tedio y la inmovilidad generan en aquel momento clave un modo propio y melancólico de vivir la ciudad como "entre visillos" (para aludir a la significativa obra de Martín Gaite, publicada en 1958). En efecto, entonces también se dijo por un ocasional habitante de Salamanca, el escritor Martín Santos, que los hombres podian encontrar en tal ciudad "no sólo su determinación como persona y su razón de ser, sino también los impedimentos múltiples y los obstáculos invencibles que le impiden llegar a ser"4. Ello probaba, por lo demás, la carga de verdad que Unamuno había situado a principios de siglo en un texto fundamental y explícito: Sobre la influencia respectiva de las grandes y pequeñas ciudades en la formación del espíritu (1908) ${ }^{5}$.

Salamanca, en esto de mostrar por entonces su influencia fascinadora a las clases intelectuales españolas, tampoco seguirá el ejemplo que en Europa dieron antes y por entonces un puñado representativo de "ciudades muertas", ciudades que arrastran una decadencia secular, sin ser tocadas nunca por el viento del progreso industrial o siquiera comercial, y que, entonces, en su condición detenida, suspensa, exaltan con una cierta belleza podrida a los intelectuales sensibles. No. Antes bien, se diría que su para siempre agostada entraña contrarreformista, eclesiástica y franquista, cortó en seco cualquier acceso benevolente a su espiritu definitivamente malherido, pero siempre áspero, altivo, antipático con el viajero y visitante, cosa que se encargaron de revelar desde muy pronto los espíritus europeos refinados, desde Norberto Caino hasta Mario Praz en su Península pentagonal, donde se maltrata elocuentemente la entraña hostil y antimoderna de la capital de provincias hispana. Como rezaba de manera muy metafórica el título del escritor Manuel San Martín en una novela dedicada a Salamanca en los primeros sesenta: en efecto, La luz pesa.

Enlazando con la decadencia postbarroca, son éstos los años del profundo olvido simbólico, el cual ocurre por paradoja increíble en la ciudad misma que se podía autorrepresentar en otros tiempos como ideal república de las musas y gran anfiteatro donde se mostraba en estado puro el ser y el genio de una nación imperial.

Fueron aquellos, ciertamente, los años pobres, los años del abandono por parte de las máquinas administrativas que, por aquel enton- 


\begin{tabular}{l} 
Investigación \\
La ciudad de la memoria. \\
Devenir de los discursos \\
de representación \\
Fernando R. de la Flor \\
\hline
\end{tabular}

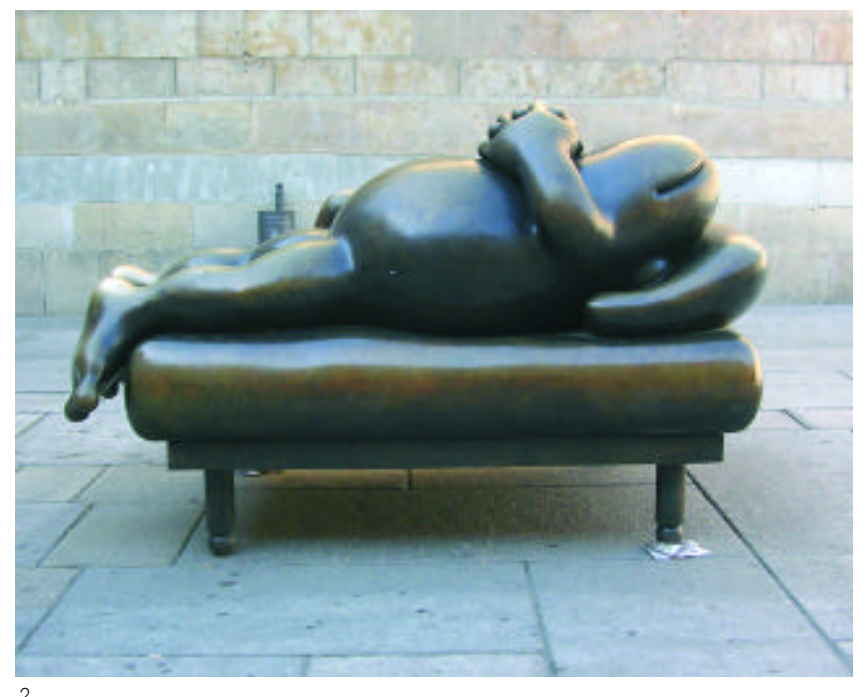

2

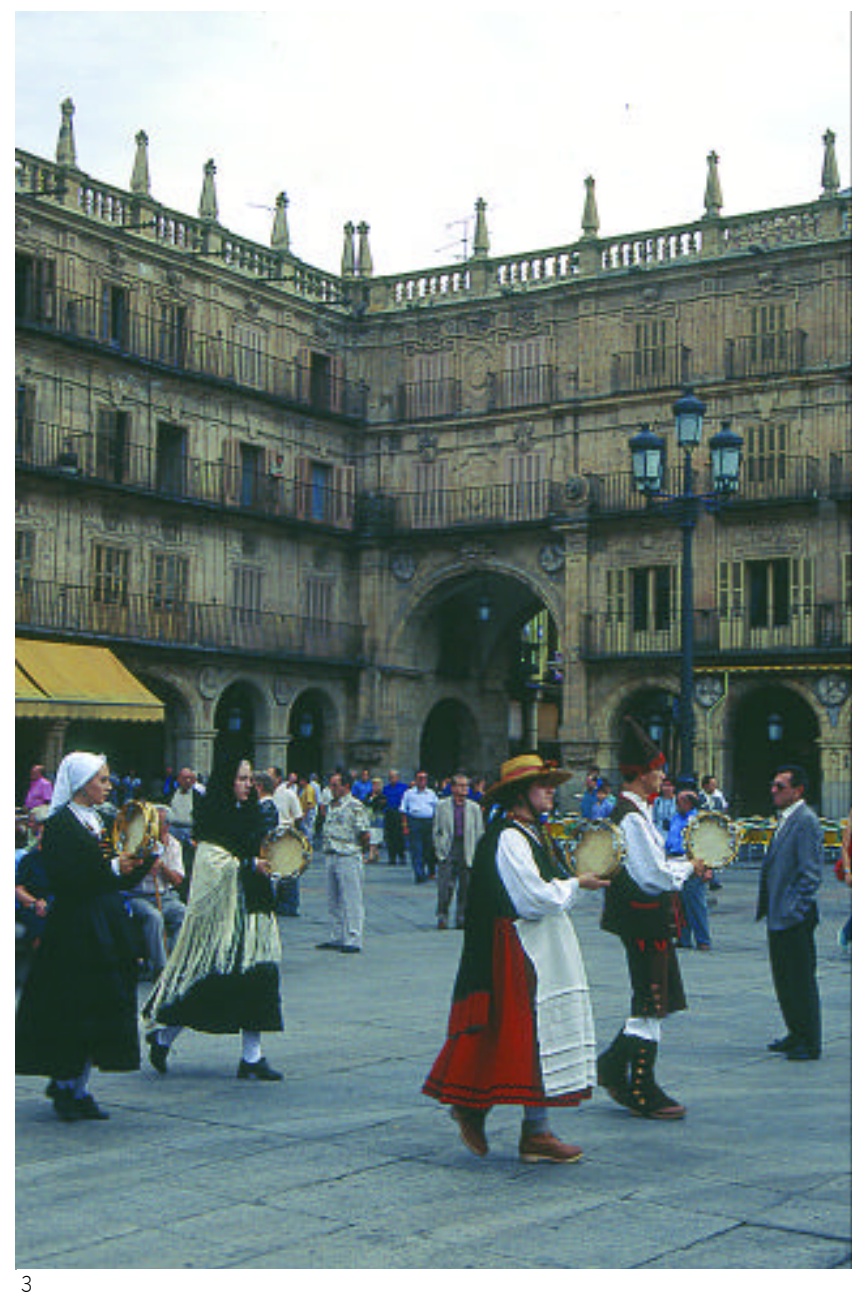

2. El cambio de signo de la ciudad patrimonial busca transferir la carga trágica, la pesada herencia histórica de carácter absolutista y confesional que le cabe en tanto antigua ciudad hispana de naturaleza clericalizada, levítica e inquisitorial, ahora conducida hacia un review o disposición renovada de apertura lúdica

3. Alguien tendrá algún día que historiar el modo en que las catedrales contrarreformistas y, sobre todo, la gran plaza ilustrada, construida por el "caballero" Llanes en la Salamanca más clásica, sivieron como ideal telón de fondo a las primeras y potentes mascaradas político-religiosas de carácter nacional

ces, años cincuenta, sesenta, habian ya decidido emplear sus energías de progreso y de cambio en otras zonas más atractivas del país; alli donde una geografía más dúctil y un espacio sin la carga de memoria histórica que llevan, de una manera un tanto agónica, las tierras de Castilla, soportaría por entonces mucho mejor la espiral de transformación acelerada y de cambio sin reversibilidad en que se vio envuelto pronto gran parte del país y del paisanaje.

\section{El espacio espiritual de la ciudad}

Esta Salamanca dormida, y, en realidad, arruinada profundamente y muerta en sus fuerzas sociales y agentes de proyección y cambio, era entonces apenas el recurso folklórico para una fotografía y unas incipientes artes cinematográficas, además de para una pintura "tipista", que se conformarian largamente con evocar, con rasgos a la fuerza elegiacos, el hinc fuit Salamanca.

Los edificios fantasmas de la antigua Ciudad de los Estudios, captados aquellos aquí y allá en pinceladas y tomas obtusas, no denunciaban nada, como por entonces era fiel costumbre, sino que, en realidad, saludaban inconscientes el inesperado regalo que a los ojos de tal generación de "artistas" suponía el que se produjera alli mismo aquello que Marx preconizaba para unos tiempos por venir en que necesariamente: "Todo lo que antes era sólido debiera -al fin- disolverse en el aire"6. Las bellas arquitecturas -había dicho Ruskin- producen más bellas ruinas ${ }^{7}$.

El pasado de Salamanca, casi dicho en términos benjaminianos, adoptaba en esto un gesto patético, una facies hipocrática 0 , incluso francamente cadavérica, a la que por entonces las todavía inexistentes operaciones de lifting restaurativo no podian librar de los aspectos terminales que comenzaba a mostrar por todos lados un patrimonio que se había quedado sin defensores, aún cuando conservara todavía a sus rapsodas.

El silencio político impuesto permitió por entonces el que, si bien la piel de toro se remozaba y cobraba nuevos tonos, el viejo espíritu de la misma agonizara sin los sacramentos de la denuncia, en los grandes pueblos sombríos y en puntos tétricos que habían constituido el corazón (ahora infartado) de España. Pueblos entre los cuales Salamanca cobraba por entonces un valor de símbolo y de metáfora de una peculiarísima angustia hispana por no saber encontrar en la memoria del ayer el fundamento de los sucesivos futuros que empezaban a insinuarse en el horizonte.

Pero esta dormición y esta paz anestésica que le fue recetada a la ciudad y, en definitiva, aquello que hoy puede leerse con más benevolencia como un período de tregua concedida por entonces a su caserío, en donde, por la pura osamenta, todavía podía reconocerse al cuerpo que encarnó en tal despojo, fue pronto sentida como un descanso y en realidad como una lapso que el pasado se tomaba 
antes de venir a desaparecer, expulsado de los sagrados lugares donde había secularmente residido.

Entonces, a lo largo de los sesenta e intensificándose el proceso en los años setenta, la ciudad sale bruscamente de su limbo preservativo, y abandona aquella "campana de cristal" en la que había sido separada del aire contaminante del progreso y la transformación.

Antes de que esto se produzca, o justamente en los momentos en que empieza a acaecer, la cámara melancólica de Basilio Martín Patino realiza la elegía coetánea de la ciudad, al convertirla, no diríamos en "fondo", sino en auténtico leit-motiv de un filme que ha sido reconocido como extraordinario, y que nosotros, ahora, desde nuestra particular perspectiva, habremos de considerar como el documento veraz y la radiografia de las interacciones que se producen entre arquitecturas, modelo urbano y el propio clima moral de los ciudadanos.

Desgranándose en fotogramas fijos, el ayer de Salamanca se mostraba por última vez allí, antes o en el preciso momento en que el proceso de desarrollo económico generalizado en el país de aquellos años dejara sentir sus efectos en una ciudad habitada casi en exclusiva por clases pasivas y funcionarios, al lado de unos comerciantes empeñados en mantener las esencias arcaicas de un paisaje de contornos casi precapitalista.

Los restos del naufragio histórico emergían aquí y allá con sus poderosas descarnaduras en la superficie rota y fracturada de la ciudad de Salamanca, punteando obsesivamente el relato melancólico que un temprano desencanto trenzaba en Nueve cartas a Berta, un monumento en imágenes a una caída o decaída Salamanca a fines de los 60. Desde la evocación de los prostibulos celestinescos, que habían hecho legendaria la "Ciudadela del Saber", hasta la estructura intocada del pobre comercio profundamente provinciano, las postales móviles de Basilio Martín Patino ofrecian un viaje fascinante por el pasado y, en él, los travelling parecían montados por ese propio "ángel de la historia" que, pintado por Paul Klee y evocado por Benjamin, sabemos con certeza que ingresa en el futuro, movido por el viento del progreso, pero cuyo rostro de modo inevitable se detiene en observar, con espanto, el territorio de ruinas en que se ha convertido el pasado.

En esa suerte de galería fúnebre y espectral en que se habian convertido los grandes edificios patrimoniales; en aquella sucesión de estancias deshabitadas, "cuarteles robados" de la historia, otrora gloriosa, la mirada crítica del cineasta ofrecía un documento arqueológico, fundamentalmente de orden arquitectónico y urbanístico, pues allí los aspectos constructivos cobraban una suerte de dimensión sicológica, constituyendo casi en términos unamunianos una suerte de un todo con el espíritu del tiempo, viniendo a constituir, en efecto, el "cuerpo" de las almas, la envoltura de piedra.

En aquella historia propiamente inmortal, gestada en los 70, la ciudad se revelaba por última vez como un palimpsesto, donde la escri- tura de la historia se amontonaba en estratos apretados, y en cuyo suelo original y primero se encontraba, como légamo fecundador de futuros que luego no terminarian de llegar, una España imperial y cesárea. A lo cual, además, había que añadir el proyecto humanista al cabo dramáticamente abortado casi en flor, pero que podemos suponer que dejó, en la figura señera de un Fray Luis, literalmente impregnadas las piedras (y mucho más que ellas mismas: las propias memorias y en realidad todo recuerdo de Salamanca, que alli dondequiera se produzca opera su abertura con una cita del gran fraile y poeta). La Celestina, también, y, con ella El Lazarillo, cerraban esa tríada renacentista, expresión de un pensamiento crítico, que a la postre habría acabado sin descendencia como representante de un mundo finalmente vencido, ello en una ciudad que desde muy pronto había terminado por ser "reducida" a la ortodoxia y a la obediencia estricta, al convertirse en una suerte de "capital" moral del pensamiento absolutista y confesional.

En seguida también, pues, a estas fuertes presencias evocativas, hombres y destinos poderosos mezclados, se debe unir la fuerte impronta ambiental y las muestras físicas exorbitadas del poder de una Iglesia.

Iglesia que presentaba precisamente aquí su signo abiertamente contrarreformista -vale decir retóricamente dispuesta a inducir el asombro y la aceptación de sus valores por vías acríticas e impositivas-; tupido tejido eclesial que, en el Barroco, y aún entrado ya bien el Siglo de las Luces, quemaría en esta sede privilegiada de su poder sus energías simbólicas y su propia capacidad poética en un arte vehemente e impresivo.

A ese arte "espiritual" que caracterizará para siempre a la ciudad del Tormes, sirvieron por entonces con entrega generaciones de artistas "churriguerescos" -"góngoras de la piedra", como bien fueron llamados burlescamente-, contra los que una aufklärung y un criticismo europeo, encarnado en un Jovellanos con implicaciones reformistas en la ciudad, había ya en su tiempo reaccionado, acusándoles severamente de cometer solecismos bárbaros con las artes del espacio, además de haber perpetrado figuras retóricas monstruosas mediante su trabajo de ataracea de la piedra. Todo lo cual hacía de los García de Quiñones, de los Sagarvinaga y de los innúmeros Churrigueras merecedores de un apelativo degradador, que casi hasta nuestros días ha constado en realidad como un baldón en la historia del arte nacional: Sí. Ellos eran los despreciados "jerigoncistas salmantinos", los autores de un arte degradado, donde venían a extraviarse definitivamente las puras líneas de un Renacimiento que entre nosotros habia durado el tiempo justo de una primavera fugaz.

Se produce, en los caminos por donde Salamanca vino a ser lo que hoy imaginamos que es, una ironía de la que tanto gusta la propia historia, la cual en ocasiones subvierte las categorías estéticas para poder, finalmente, monumentalizar todo pasado, aún cuando ese pasado fuera un día un presente al que no se le reconocía futuro algu- 


\section{Investigación}

La ciudad de la memoria.

Devenir de los discursos

de representación

\section{Fernando R. de la Flor}

no. Pues bien, dos siglos después de haber sido rechazados por el canon estético ilustrado y "moderno" estos frutos tardios del barroquismo de una ciudad que como Salamanca se había entregado entusiasta al delirio churrigueresco en sus retablos y fachadas maestras, es la propia Europa la que abraza a aquellos en cuyo nombre antes se había expulsado de su seno.

Bien es cierto que, entre nosotros, y a la temprana altura de los años 20, ya Eugenio D'Ors había previsto ese momento reivindicativo de lo más propiamente delirante y castizo de este arte hispanísimo que en Salamanca había dejado la huella de su talento sobresaliente y casi bárbaro:

"Churriguera -había escrito el gran crítico-, arquitecto maldito, sirena deliciosa... Tus altares en las iglesias hispanas, tus portales, tu salmantina casa municipal, me traen y traerán un dia al mundo, con el deslumbramiento tumultuoso de tu pasión, con todo su mal gusto, un trágico cantar de abismo y de océanos... preveo para Churriguera, en hora próxima, una justiciera venganza"8.

Las sectas o dinastías de arquitectos barrrocos salmantinos, como reconocería de un modo explícito el acta de nombramiento de la ciudad como Patrimonio Universal del año 89, han sido, en realidad, los "ingenieros líricos" (diriamos con palabra autóctona: los oríices) de la peculiaridad constructiva de la ciudad, y a ellos se debe su más impresiva imagen, en definitiva. Al menos aquella imagen que, en conexión con el espiritu unamuniano, muestra abiertamente el genus loci (el aura investida), su preconizado carácter de ciudad "espiritual" y, como tal, arrebatada y turbulenta en sus quiméricas aspiraciones "hacia lo alto".

Tal "alto soto de torres" (Unamuno) es, así, el producto tardío de unos artistas desequilibrados y retardatarios, ya en su propia época, que se habrían refugiado en una ciudad cruzada por una determinación esencialmente conservadora, antimoderna, para ejercer al servicio de la Iglesia las grandilocuencias a que los llevaba su muy castizo espíritu. Entonces pudieron entregarse con energías admirables a la construcción de un tipo singular de espacio, que Azorín definiría tiempo después con dos adjetivos mordaces, cuanto sumamente precisos: "tétricos y católicos"; "estilo tétrico y católico", pues. Esa es la determinante estético-moral que marca férreamente con su signo distintivo el cuerpo de piedra de la ciudad.

Los Churriguera representan el cosmos mismo de las inquietudes barrocas y desmedidas, grabándolo en piedra en la topografía de su ciudad y capital simbólica, y repletándola, como escribe Severo Sarduy, de una cornucopia en que abundan los "emblemas florales, los nudos y las flechas, orlas y volutas, lámparas mudéjares que oscilan; capiteles de frutas sefardies, retablos virreinales y espesas coronas góticas suspendidas sobre remolinantes angelotes tredentinos" .

Y es por ello, pese a esa aversión "ilustrada" ("el ornamento es delito", al cabo), que tales artistas cosecharon, que no puede dejar de decirse que en las torsiones, gallonados, gallardetes y flámulas de piedra de que supieron cubrir el espacio aéreo de la ciudad estos arquitectos del exceso racial, el cual llevan impreso (o esculpido) incluso en su nombre dinástico, hemos al fin aprendido a reconocer la existencia posible de un mensaje metafísico que, todavía, en alguna tarde singular por los tonos potentes que pueda imprimir un ocaso, revela súbitamente la esencia desgarrada en que funda siempre su estatuto la comunidad de los hombres.

De esta "aura metafísica", que el hecho mismo de la existencia de una específica teología salmantina avala, se beneficia extraordinariamente la ciudad soñada que Salamanca siempre es, por encima de cualquier contingencia epocal: pues la ciudad vive, todavía -y al menos alli permanece inmutable su imagen- alojada en los discursos del exceso que genera.

Y, en todo caso, en el entorno muy próximo de algunos de sus hitos arquitectónicos extraordinarios, la vieja urbe teológica, la "república de las letras" con que soñara Saavedra Fajardo, opone aún su "energía de pasado", manteniendo fiel y firmemente la afirmación de sus valores. En las Escuelas Mayores, en la Clerecía de San Marcos, en San Esteban, en el Colegio de Calatrava, en sus cuerpos de campanas, como el de la Catedral, en algunas logias y claustros, como el "de profundis" y cementerios de teólogos, todo el espíritu de pasado se repliega hacia lo que son ya sus últimas posiciones. De estos lugares emanativos, auráticos, arrastrados fatalmente hacia el seno de un malenström desacralizador, se puede decir que suponen la encriptación definitiva de una memoria perdida.

\section{La estructura de los recuerdos se parece a la de una ciudad en ruinas}

Mientras eso ocurría, y ocurre todavía, en los "cielos de la ciudad", por aquellos mismos años setenta, y luego también en los ochenta democráticos, la ciudad se entregó entusiasmada e ingenua a un lavado integral de su pasado, indistintamente, reciente o lejano, pues se trataba por entonces de homologarse con un futuro al que se pudiera ingresar sin demasiadas rémoras. Todo empezó con una operación de aislamiento del verdadero núcleo poderoso de la ciudad arcaica, al que literalmente por entonces se le puso en "estado de sitio".

En una operación urbanística, que los teóricos americanos de la modernidad han denominado como wrapping (encapsulamiento, encriptamiento), el desarrollismo violento acabó imponiendo su nueva lógica de predominio visual desde los nuevos ejes de desarrollo que crearon las recién abiertas "rondas" de la ciudad. En este efecto "envoltura", que supuso la preservación y el aislamiento de un pasado intocado dentro de una realidad presente sumamente cambiante, la ciudad moderna ciñó por completo el tejido del castizo caserío salmantino, mientras se deshacía o camuflaba convenientemente cualquier resto de antigüedad que cayera del otro lado de esa frontera del tiem- 
4. Los edificios fantasmas de la antigua Ciudad de los Estudios no denunciaban nada, sino que saludaban inconscientes el inesperado regalo que suponía el que se produjera alli mismo aquello que Marx preconizaba para unos tiempos por venir en que necesariamente: "Todo lo que antes era sólido debiera -al fin- disolverse en el aire"

5. A lo cual, además, había que añadir el proyecto humanista al cabo dramáticamente abortado casi en flor, pero que podemos suponer que dejó, en la figura señera de un Fray Luis, literalmente impregnadas las piedras

po que establecieron entonces las rondas de circunvalación interior de una ciudad, que, incluso, se precipitó por entonces en aceptar los caminos del desarrollismo urbano antes incluso de que el tren del progreso avanzado se pudiera vislumbrar en su horizonte.

Aquí venía a realizarse con precisión inversa el lema que, enunciado por Ford, habría de conducir la revolución industrial de este siglo: "Hagamos los coches, luego ya vendrán las carreteras"

En lo términos siempre precisos de los poetas de entonces, la elegía de la inviabilidad de una memoria de la ciudad podía expresarse en el modo confirmativo de la catástrofe: "¡Ciudad! ¡Ciudad perdida! Ya todo son murallas" ${ }^{10}$.

Un cinturón de edificios sobredimensionados comenzaron a ocultar, en un proceso ya iniciado con brutal energía en los sesenta, la realidad de un perimetro urbano histórico literalmente asfixiado, y al que, al menos en los primeros momentos, se desatendió profundamente, degradándose dentro de él la vida urbana en los fenómenos bien conocidos de la explosión de la delincuencia y la droga, que durante un tiempo que pareció eterno señoreó las oscuras calles por donde antes se había paseado la sombra de Celestina o del mismísimo "estudiante de Salamanca". Fue entonces, en medio de esa derrota en toda regla de la tradición "clásica" salmanticense, cuando la ciudad perdió, en términos del urbanista Marconi, su "forma simbólica".

El epicentro mismo donde habría venido a concentrarse el "espíritu fuerte" de la ciudad; lugares como la Cueva de Salamanca, la Iglesia de san Cebrián, el Colegio de Pan y Carbón, el convento de la Merced, las ruinas confusas del Trilingüe, las construcciones subterráneas y los despojos de decenas de "lugares de memoria", como las casas de los Nebrija, de los Churriguera, de los Comuneros... sufrieron entonces sus últimos menoscabos. Ya no se repondrian de estas condenas inexplícitas, dictadas por el espiritu de un tiempo que, como Saturno, devoraba ahora a sus hijos más granados; más adelante, sólo un puñado de construcciones aleatorias alcanzaría a ser mal recompuestas con intervenciones quirúrgicas in extremis. Algo que cambió por completo el aura turbia y singular de estos lugares, convirtiéndolos en ejemplos maestros de lo que fueron las primeras políticas restaurativas, prácticamente carentes de sentido histórico, y deseosas sólo de poner en rentabilidades (políticas o económicas) los edificios sobre los que por entonces con una urgencia fingida se actuaba.

Entonces, la Antigüedad, el fantasma mismo del Tiempo Pasado, tuvo que retroceder forzosamente hacia los interiores y lugares más oscuros e impenetrables de la ciudad, viniendo a residir en lugares peculiares, en elementos insólitos (columnas truncadas, claustros incompletos, escaleras olvidadas, capitales insensatos, bóvedas ocultas por falsos techos, pozos hondos a los que se había arrojado la llave de la memoria...) que estaban y están ahí para dar testimonio de lo que la pequeña Roma española fue. En torno a ellos, se produce un aura, cuyo fulgor de fragmento y de tesela definitivamente arrui-
6. Y, en todo caso, en el entorno muy próximo de algunos de sus hitos arquitectónicos extraordinarios, la vieja urbe teológica, la "república de las letras" con que soñara Saavedra Fajardo, opone aún su "energía de pasado", manteniendo fiel y firmemente la afirmación de sus valores
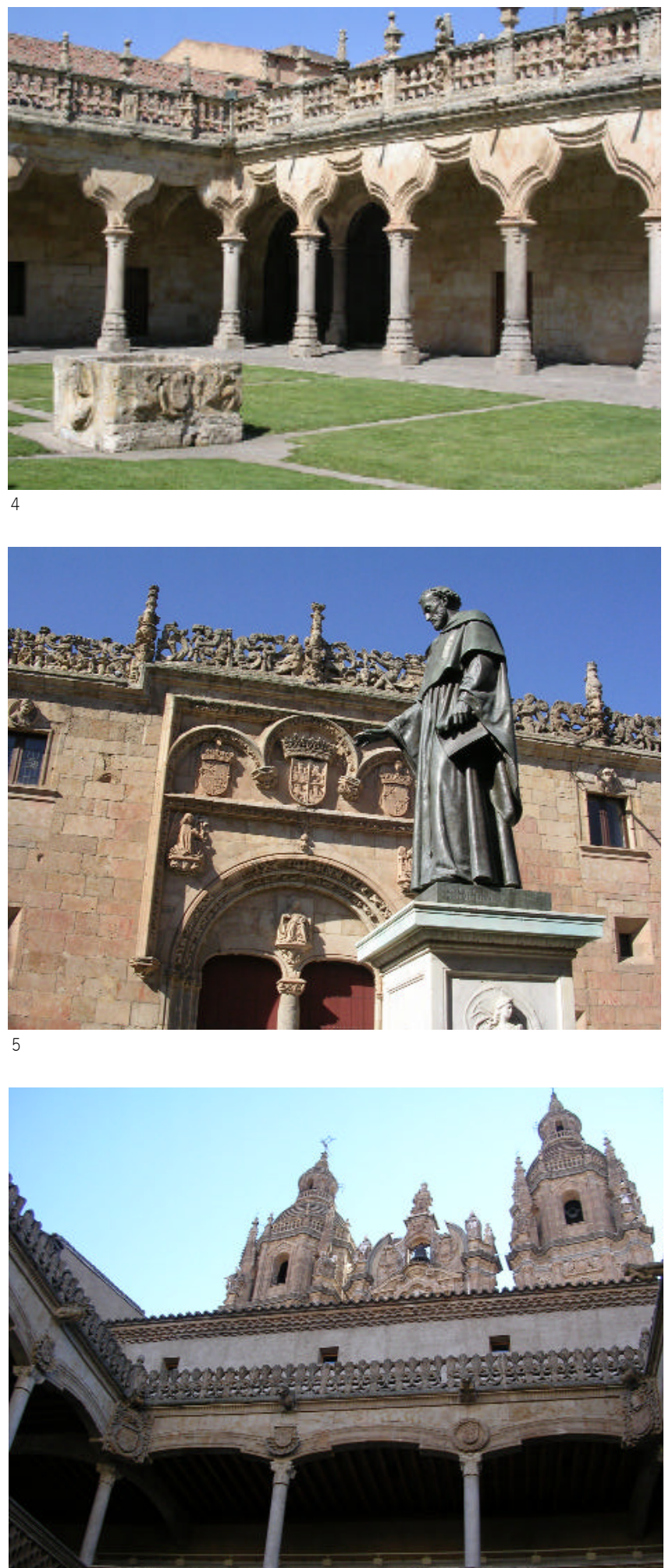


\begin{tabular}{l} 
Investigación \\
La ciudad de la memoria. \\
Devenir de los discursos \\
de representación \\
Fernando R. de la Flor \\
\hline
\end{tabular}
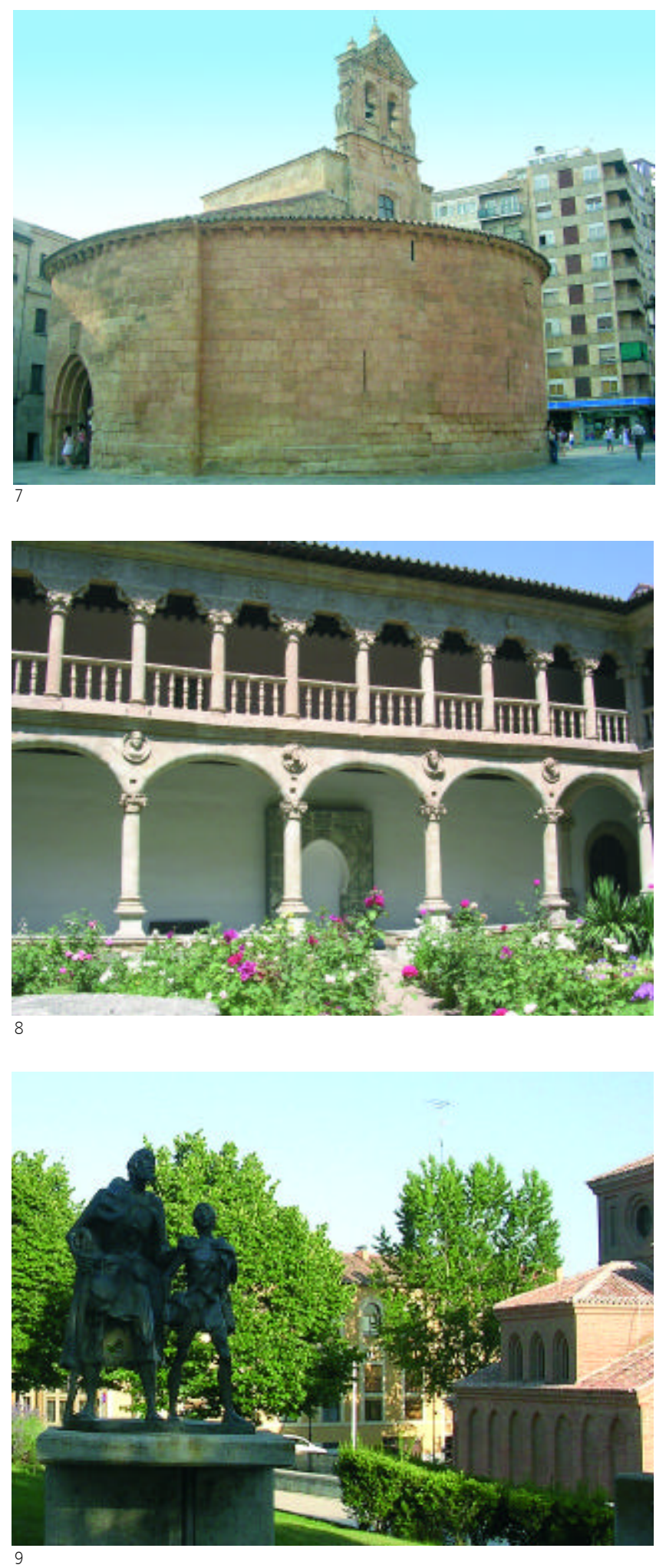

7. En una operación urbanística, que los teóricos americanos de la modernidad han denominado como wrapping, el desarrollismo violento acabó imponiendo su nueva lógica de predominio visual desde las recién abiertas "rondas" de la ciudad

8. Entonces, la Antigüedad, el fantasma mismo del Tiempo Pasado, tuvo que retroceder forzosamente hacia los interiores y lugares más oscuros e impenetrables de la ciudad, viniendo a residir en lugares peculiares

9. Las mismas riberas fueron en buena parte destruidas con el objeto banal de crear en ella un hinterland, una tierra de nadie. En el borde mismo de esta frontera en desorden, se colocó una estatua del Lazarillo de Tormes y eso pareció por entonces suficiente

nada fuera descrito en su día por Marcel Proust, aunque en su caso referido a las columnas de la Piazzetta de Venecia. En efecto, alli:

"A su alrededor, los días actuales, los días que estamos viviendo, giran, se apresuran, zumbando en torno a las columnas, pero al llegar junto a ellas se detienen bruscamente, huyen como abejas espantadas; pues ellas, estas esbeltas y delicadas esclavas del pasado, no pertenecen al presente, sino a otra época donde el presente tiene prohibido penetrar. Alrededor de las columnas rosas, de donde brotan sus espléndidos capiteles, los días actuales se apresuran y zumban. Pero interpuestas entre ellos, los apartan, preservando con su delgado espesor un lugar de inviolabilidad del Pasado: del Pasado familiarmente surgido en medio del presente, con ese color un poco irreal que tienen los objetos que una especie de ilusión nos hace ver a pocos pasos, cuando en realidad se encuentran a muchos siglos de distancia, dirigiendo todas sus facetas, tal vez demasiado directamente a la mente, exaltándola más que si se tratara de un espectro de una época sepultada en el tiempo; y que no obstante está ahí, entre nosotros, próximo, codeándose con nosotros, tocándonos inmóvil, a plena luz del día"11.

\section{Lifting urbano}

La época de inhabitación de lo que ya no podría más llamarse "ciudad antigua", sino tal vez sólo, como empezó a hacerse común en los folletos, "barrio antiguo", y, en realidad, conjunto de hitos dispersos por una geografía de perdida coherencia, duró poco, pero fue extremadamente dañosa para esa Salamanca histórica de la que tanto se hablaba ya, mientras que simultáneamente podía desaparecer, literalmente tragada por sus ruinas y evaporada más tarde por la proliferación de reconstrucciones historicistas -y, por veces, dantescas-, de lo que habian sido sus hitos significativos.

Entonces se pudo decir con certeza, incluso por quienes habían sido sus reconstructores, que la mirada se instalaba definitivamente ante un "paisaje de barrios mártires, que yacen muertos e insepultos, a los que se ha dejado como carroñas para que se calcinen al sol" (Chueca Goitia) $^{12}$.

Se trataba, en efecto, del wrapping, la dinámica aisladora mediante la cual estaba escrito que una ciudad nueva iba a crecer despreciando absolutamente el solar primitivo en que se sustentaba su ser, y que conformaba el "pilar" de toda su historia posible, a lo que también debemos unir la intención de rodear el núcleo duro del pasado, abandonándolo paralelamente a sus dinámicas destructivas propias, que determinó la existencia de una ciudad antigua literalmente consumida por las tensiones explosivas que en su interior producia un vecindario sumamente conflictivo y, en realidad, en plena desbandada y saldo de sus tristes posesiones. Esto sucedía en un medio que, incomprensiblemente, había visto descender su calidad de vida a varios grados bajo el cero de lo que fuera incluso una posible normalidad en el Tercer Mundo. 
Imágenes: Martín J. Fernández, Salamanca (1. Vista de la catedral desde el Convento de las Dueñas; 2. Rana. Exposición temporal "Salamanca 2005, Plaza Mayor de Europa"; 3. Bailes tradicionales en la Plaza Mayor; 4. Patio de las Escuelas Menores; 5. Escultura de Fray Luis de León, frente a la fachada de la Universidad; 6. Torres de Clerecía de San Marcos -Universidad Pontificia- desde el patio de la Casa de las Conchas; 7. Iglesia de San Marcos, al pie de la calle Zamora y de la Avenida Torres Villarroel; 8. Claustro del Convento de las Dueñas; 9. Monumento al Lazarillo de Tormes).

A las potencialmente destructivas tensiones interiores de ese "casco" o barrio" o "centro" descentrado, hay que sumar en estos años de liquidación por derribo el hecho mismo de que las sagradas perspectivas, las cuales verdaderamente construyen la realidad de aquello que podemos llamar una ciudad, que siempre toma asiento en un territorio y en una peculiar geografía, fueron radicalmente amputadas en sus tres cuartas partes. En realidad, sólo se vino a salvar, como diria un poeta de aquellos "últimos días" de la Salamanca clásica, la fachada al poniente de la "república literaria", el rostro cansado de la ciudad que caía desfallecido hacia el río como "brillante joya que claudica hacia poniente" ${ }^{13}$.

Pero ni siquiera esta fachada, la más tradicional de tal ciudad, podemos decir que ha conservado el gesto característico de su morfología primitiva. Las mismas riberas fueron en buena parte destruidas, sin objeto aparente, o más exactamente con el objeto banal de crear en ella un hinterland, una tierra de nadie, que cortó por entonces el tradicional diálogo sereno de la ciudad con su río milenario, entretanto él mismo también malherido. En el borde mismo de esta frontera en desorden, se colocó una estatua del Lazarillo de Tormes y eso pareció por entonces suficiente.

\section{Futuro pasado}

Este resumen apresurado empieza a traernos al presente, en el que se produce la autocomplacencia por el éxito turístico y el relanzamiento que la ciudad experimenta, sobre todo en los planos simbólicos de los discursos de representación (que entretanto no han dejado de incrementarse). Ello no nos puede hacer pasar u olvidar una tendencia patológica que dentro de esta cápsula intensa finalmente también habita, y que la hace en cierto modo un objeto propiciatorio. Esta ciudad de las evocaciones, Salamanca, protomodelo pasadista, es uno de esos lugares donde lo presente se encarniza de modo singular con lo pasado y le muestra su poder aniquilador, presa de un resentimiento que en buena medida es histórico, y que aquí creo que no caprichosamente hemos vinculado expresamente con una pulsión de signo fascista.

La ciudad ha sufrido en su carne victimaria los largos años de la Transición y las perplejidades y titubeos a que ese tiempo ha condenado a quienes han vivido dentro de él, han sido somatizados los tales años por el tejido urbano, que al fin muestra ser una coagulación de lo político. Las huellas de todo ello son visibles por doquier, sobre todo en el aspecto desorganizado, sectorial de las políticas de conservación, de desarrollo, de recuperación aquí llevadas a cabo. De todo lo cual resulta una evidencia: la de que en su propio hábitat se muestra, como quizá en parte alguna de la geografía española, la irresolución determinante que afecta a esta época de desconciertos varios.

De este presente se diría sobre todo que ya no es capaz de "despertar al pasado", sino sólo de evocarlo y llamarlo débilmente.

Momento, pues, en que la cuestión misma de ese pasado -el qué hacer con el pasado- cobra entre nosotros una dimensión trascenden- tal, al tiempo que esto se oculta y todo se entrega a un nuevo guiño modernizador, reparador, europeizante y turistificable.

Con todo, el gesto impresivo que el pasado grabó a sangre de toro en la memoria inmaterial sobrevive. Las potentes masas arquitectónicas determinan en Salamanca todavía una presencia de lo bien podríamos suponer que es ya todo ausencia. Los antiguos dioses, las divinidades lares, ciertamente, han deshabitado la ciudad, pero como percibiera Heidegger ante el templo derruido de Apolo en Basa, siempre queda la huella mnémica, queda la presencia inmaterial de la ausencia sobrevenida.

La destrucción activa a que se entregó el espacio histórico en una fatal hora de España, y ya, al día de hoy, el trabajo del cambio de signo de las cosas, no puede acabar del todo con la historia que lleva el agua bajo los ojos del puente ¿romano?

El ángel de la historia, que es el ángel de la elegías y de las Elegías $(\text { Rilke })^{14}$, y que es esa criatura que reaparece ya plenamente cumplida la transformación de lo visible en invisible, sobrevuela aún la ciudad en algunas mañanas de nieblas o en los crepúsculos del verano de Castilla, alentando, con el ruido con que rasga un intocado espacio del aire, un cierto revivir de las memorias dormidas y, en realidad, perdidas y acá y allá fragmentadas en medio de la marea del presente absoluto.

\section{Notas}

${ }^{1}$ Rosario Asunto, "El revival y el problema del tiempo", en G.C. Argan (ed.), El pasado en el presente. Barcelona, Gustavo Gili, 1974.

${ }^{2}$ Marinetti et alt, Futurismo. Manifiestos y textos. Buenos Aires, Quadrota Editorial, 1994.

${ }^{3}$ Paul Virilio, Estética de la representación. Barcelona, Anagrama, 1988, 67.

${ }^{4}$ Luis Martin Santos, Tiempo de destrucción. Barcelona, Seix barral, 1975, 255.

${ }^{5}$ Miguel de Unamuno, en Obra completa, IX. Madrid, Castro, 2006, 314.

${ }^{6}$ Cito el libro de Marshall Berman, Todo lo sólido se desvanece en el aire. La experiencia de la modernidad. Madrid, Siglo XXI, 1988.

${ }^{7}$ John Ruskin, Las piedras de venecia. Valencia, Soler, 2000, 92.

${ }^{8}$ Eugenio D’ Ors, Lo barroco. Madrid, Aguilar, 1967, 98

${ }^{9}$ Severo Sarduy, Barroco, en Ensayos generales sobre el Barroco. México, FCE, 1987, 159.

${ }^{10}$ Aníbal Núñez, Alzado de la ruina, en F.R. de la Flor (ed.), Obra poética, I. Madrid, Hiperión, 1995, 389.

${ }^{11}$ Marcel Proust, En memoria de las iglesias asesinadas, en Los placeres y los dias. Parodias y miscelánea. Madrid,. Alianza, 1975, 249.

${ }^{12}$ La destrucción del legado urbanístico español. Madrid, Espasa Calpe, 1977, 37.

${ }^{13}$ Anibal Núñez, Alzado de la ruina..., 367.

${ }^{14}$ Elegias de Duino. Barcelona, Editorial El bardo, 1972. 